\title{
A note on predetermined earthquake damage scenarios for structural health monitoring
}

\author{
Vlado Gičev ${ }^{1}$ and Mihailo D. Trifunac ${ }^{2, *, \dagger}$ \\ ${ }^{1}$ Department of Computer Science, University Goce Delčev, Tošo Arsov 14, 2000 Štip, Macedonia \\ ${ }^{2}$ Department of Civil and Environmental Engineering, University of Southern California, Los Angeles, CA 90089-2531, USA
}

\begin{abstract}
SUMMARY
It is shown that the damage scenarios for site-specific building models, responding in highly nonlinear manner to strong earthquake ground-motion pulses, can be used in real-time health-monitoring systems. When it can be shown that such predictions produce robust results and are not sensitive to the details of the complete time history of strong ground motion, the predetermined earthquake damage scenarios (PEDS) method can produce reliable predictions of the location(s) and the degree(s) of structural damage in essentially real time. It is shown that for a full-scale building, damaged during the 1994 Northridge earthquake in California, PEDS based on onedimensional wave propagation in the layered building model would have produced accurate and realistic predictions of damage. In contrast to the vibrational health-monitoring methods that track changes in the frequency and stiffness of the characteristic functions, PEDS methods provide invaluable information for spatial and temporal identification of damage. Copyright (c) 2011 John Wiley \& Sons, Ltd.
\end{abstract}

Received 9 November 2010; Revised 24 February 2011; Accepted 2 May 2011

KEY WORDS: earthquake damage scenarios in buildings; strain localization on buildings; structural health monitoring; nonlinear waves in buildings

\section{INTRODUCTION}

Health-monitoring methods aim to identify time, location, and degree of damage in a structure responding to extreme transient events (e.g., earthquakes, tsunami, explosions, and tornadoes). Realtime health-monitoring methods require continuous recording of the dynamic response, combined with software algorithms that can identify dangerous changes in system parameters as those occur and that, when those exceed the preset thresholds, can be programmed to produce required alarms and to initiate the desired action. The real-time health-monitoring methods are based on the analysis of observed changes in the vibrational parameters of response [1,2], changes in the wave-propagation parameters $[3,4]$, or a combination of those [5-9], while those changes occur or few seconds thereafter. The resolution and the reliability with which the changes are identified will depend upon the ability of the method and the location and the density of the measuring stations.

In this paper, we explore the possibility of increasing the resolution, the decision speed, and the reliability of the real-time identification of damage by storing into the identification software a set of predetermined damage scenarios (PDSs). Those scenarios can be identified by prior nonlinear analysis of response of specific structures, and when actual events occur, they can be used to help speed up identification of the damage, especially when the available data from the real-time monitoring of response may be limited, ambiguous, or insufficient. To test the PDS method, in this paper, we predict

*Correspondence to: Mihailo D. Trifunac, Department of Civil and Environmental Engineering, University of Southern California, Los Angeles, CA 90089-2531, USA.

†E-mail: trifunac@usc.edu 
the locations, types, and amplitudes of nonlinear strains in a building model of a structure that has been damaged by strong earthquake shaking. Then, by comparing the PDS with actually observed damage, we discuss and evaluate its prediction capability.

The method used in this paper is based on the wave-propagation solution of the problem. This approach has been used in parallel with the vibrational method of solution almost since the beginning of modern earthquake engineering in the early 1930s [10-12], and it has recently been revived and received more attention [13-22]. Because the wave motion in a building will be nonlinear, we will employ the finite-difference method in our solutions [23-25]. An important advantage of working with the wave-propagation methods of solution, for both linear and nonlinear response analyses, is that the location of the maximum response and of the strain localization in the structure is preserved. The vibrational methods of solution consider only the maxima of the equivalent SDOFs [26], and thus information on where the largest response occurred in the structure is lost.

The subject chosen for this paper deals with structural health monitoring of the buildings in the near field of strong ground motion (within several tens of kilometers from the causative fault) where ground motion typically includes powerful displacement pulses. These pulses can be sudden and so large that damage occurs during the first or several first passages of the wave up and down the building [27-30]. The damage in the far field, for excitation by longer and more periodic ground motion is less common, has different nature and will not be addressed in this paper.

\section{MODEL AND NUMERICAL SCHEME}

We analyze horizontal shear deformations, $u$, in a 1D model of a seven-story building supported by a half space and excited by a vertically propagating shear wave represented by a half-sine pulse (Figure 1, right). The Lax-Wendroff [31] finite-difference scheme for the solution of this problem with accuracy $O\left(\Delta t^{2}, \Delta x^{2}\right)$, where $\Delta x$ and $\Delta t$ are the space and time increments, leads to the exact solution when $\beta \Delta t / \Delta x=1$, where $\beta$ is the velocity of shear waves [27-30,32]. With a ratio of the spatial intervals $\Delta x_{b} / \Delta x_{s}=\beta_{b} / \beta_{s}$, this requirement can be satisfied, where $x$ is the coordinate along the wave propagation (Figure 1, center right). The subscripts $b$ and $s$ designate the values in the building, with height $H_{b}$ and in the half space, respectively. The equation of motion is

$$
v_{t}=(\sigma)_{x} / \rho,
$$

and the relation between the derivative of the strain and the velocity is

$$
\varepsilon_{t}=v_{x}
$$

where $v, \rho, \sigma$, and $\varepsilon$ are the particle velocity, the density, the shear stress, and the shear strain, respectively, and the subscripts $t$ and $x$ represent the derivatives with respect to time and space.
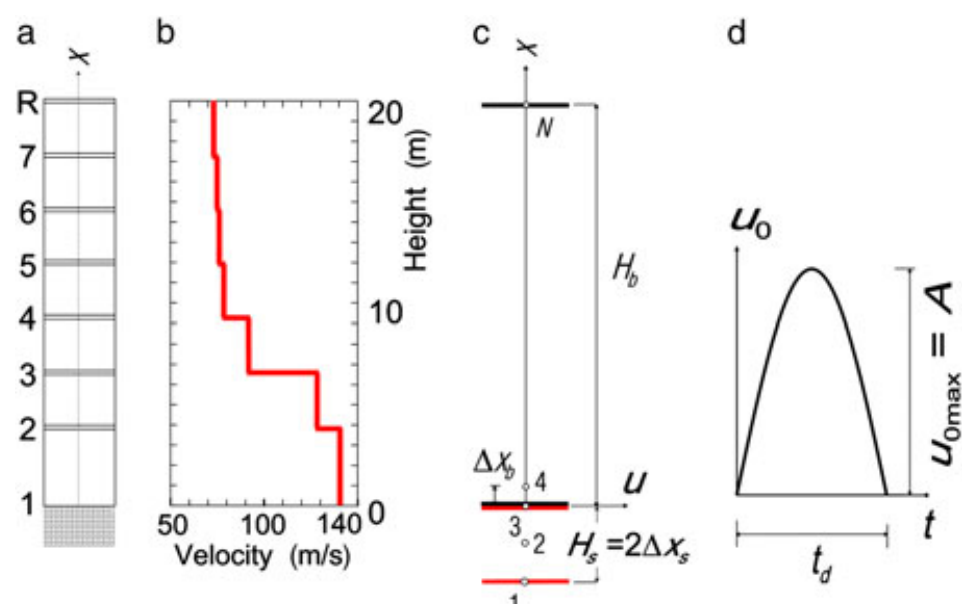

Figure 1. Building and incoming strong-motion displacement pulse: (a) layered model of the building, (b) velocity of shear waves in the layers, (c) finite difference model with transmitting boundary at node point 1 , and (d) the pulse incident from the half space. 
For shear waves, the boundary conditions (free stress at the top of the building and continuity of stress and displacement at all of the interfaces and at point 3 in Figure 1, center) and the exact transmitting boundary condition in the soil (at point 2 in Figure 1, center) have been discussed in [33] and in [28].

\section{NUMERICAL EXAMPLES}

We consider a building model supported by an elastic half space. The density and shear-wave velocity in the half space are assumed to be $\rho_{s}=2000 \mathrm{~kg} / \mathrm{m}^{3}$ and $\beta_{s}=250 \mathrm{~m} / \mathrm{s}$. In the building, these vary with height and are given in Table I. This example will illustrate the nonlinear response of a 'typical' building $[8,9]$ supported by a half space with properties that are representative of many metropolitan areas. In all calculations in this paper, we use $H_{b}=20.035 \mathrm{~m}$ and $\varepsilon_{y b}=0.0025 \mathrm{~m}$ for the maximum linear strain in the bilinear stess-strain relationship, with second slope $\gamma=0.44 \mathrm{~m}$ (Figure 2), but we present all the results in dimensionless terms.

The model we consider in this paper is a 1D idealization of a real structure. We employ the exact transmitting boundary (at point $2, \Delta \mathrm{x}_{s}$, below the ground surface; see the center of Figure 1), and thus we solve exactly the motions associated with incident, refracted, and reflected transient pulse. However, the 1D nature of our model cannot portray the 2D and 3D phenomena of soil-structure interaction (SSI) [34-38], and hence our solution is only an approximation that may provide reasonable results for longitudinal response of long buildings on elastic soil. By the nature of our 1D model, all points along the base of the structure are forced to move simultaneously, and therefore the effects of wave passage, linear differential ground motion, differential ground motion caused by liquefaction, faulting, curvature, and rocking components of ground motion will not be included in our analysis [39-47].

To describe nonlinear response in the building model, we use two dimensionless parameters:

$$
\text { dimensionless amplitude } \alpha=A /\left(H_{b} \cdot \varepsilon_{y b}\right) \text {, }
$$

where $A$ is the amplitude of the incident pulse (Figure 1, right), $H_{b}$ is the height of the building, and $\varepsilon_{y b}$ is the yielding strain in the building (Figure 2); and

$$
\text { dimensionless frequency } \eta=2 H_{b} / \lambda_{b}=2 H_{b} /\left(\beta_{b} \cdot 2 t_{d}\right)=H_{b} /\left(\beta_{b} \cdot t_{d}\right),
$$

where $\lambda_{b}$ is the wavelength of the wave in the building, $\beta_{b}=H_{b} / \sum_{i=1}^{14} \frac{h_{i}}{\beta_{i}}=99.48 \mathrm{~m} / \mathrm{s}$, is the average of the shear-wave velocity in the building, $h_{i}$ and $\beta_{i}$ are the thickness and the shear-wave velocity in the $i$ th building layer, and $t_{d}$ is the duration of the incident wave represented by a half-sine pulse (Figure 1, right).

\begin{tabular}{|c|c|c|c|c|c|c|}
\hline & $\begin{array}{l}\text { Interstory height } \\
h_{\text {interstosry }}(\mathrm{m})\end{array}$ & $\begin{array}{c}\text { Slab thickness } \\
h_{\text {slab }}(\mathrm{m})\end{array}$ & $\begin{array}{c}\beta_{\text {interstory }} \\
(\mathrm{m} / \mathrm{s})\end{array}$ & $\begin{array}{l}\beta_{\text {slab }} \\
(\mathrm{m} / \mathrm{s})\end{array}$ & $\begin{array}{r}\rho_{\text {interstory }} \\
\left(\mathrm{kg} / \mathrm{m}^{3}\right)\end{array}$ & $\begin{array}{c}\rho_{\text {slab }} \\
\left(\mathrm{kg} / \mathrm{m}^{3}\right)\end{array}$ \\
\hline Roof slab & & 0.203 & & 2000 & & 2384 \\
\hline Seventh story & 2.44 & & 73.15 & & 82.90 & \\
\hline Seventh-floor slab & & 0.215 & & 2000 & & 2384 \\
\hline Sixth story & 2.44 & & 76.20 & & 82.90 & \\
\hline Sixth-floor slab & & 0.216 & & 2000 & & 2384 \\
\hline Fifth story & 2.44 & & 77.72 & & 82.90 & \\
\hline Fifth floor-slab & & 0.216 & & 2000 & & 2384 \\
\hline Fourth story & 2.44 & & 79.25 & & 82.90 & \\
\hline Fourth-floor slab & & 0.216 & & 2000 & & 2384 \\
\hline Third story & 2.44 & & 91.44 & & 82.90 & \\
\hline Third-floor slab & & 0.216 & & 2000 & & 2384 \\
\hline Second story & 2.44 & & 129.50 & & 82.90 & \\
\hline Second-floor slab & & 0.254 & & 2000 & & 2384 \\
\hline First story & 3.86 & & 140.20 & & 76.92 & \\
\hline
\end{tabular}

Table I. One-dimensional building model. 


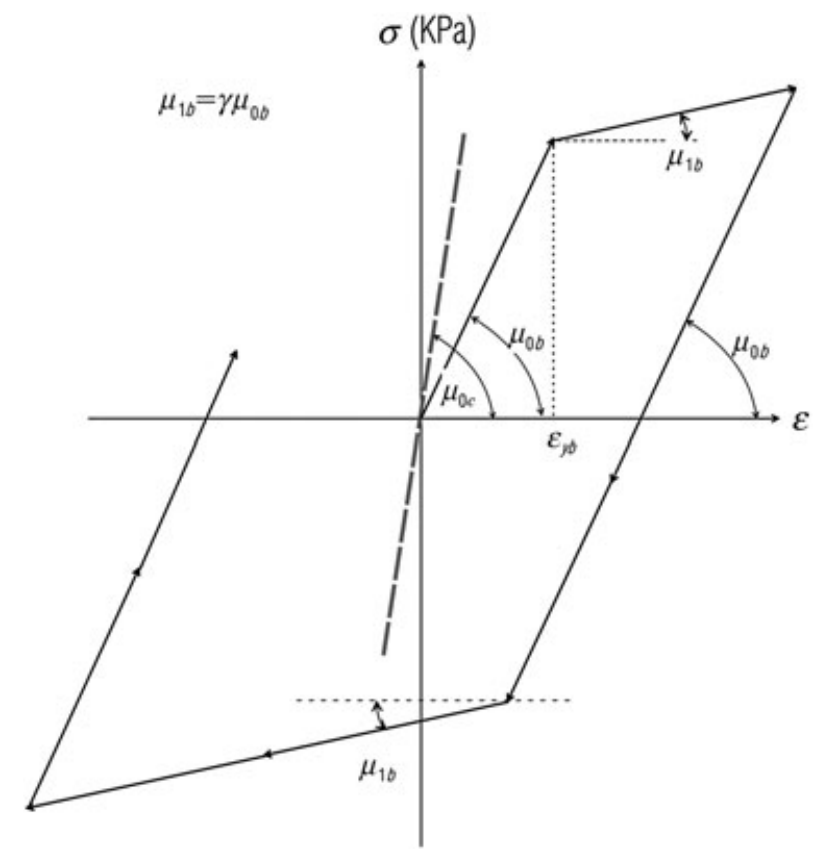

Figure 2. The constitutive law, $\sigma-\varepsilon$, for the building (solid line) and for the interface (dashed line).

Following [27-30], to represent the strains in the building in dimensionless terms, we consider $v_{\text {lin }}=v_{\text {entr }}^{\text {lin }}$, which is the maximum velocity entering the building, supposing that it is linear. The $v_{\text {lin }}$ is a linear function of $\eta$, which follows from

$$
v_{\text {lin }}=\pi A \cdot k_{t} / t_{d}=\pi \alpha \eta \varepsilon_{y b} \beta_{b} k_{t} .
$$

Then, instead of describing the absolute maximum of the strain, we will consider the normalized maximum strain,

$$
\varepsilon_{\text {norm }}^{\max }=\varepsilon_{\max } \beta_{b} / v_{\text {lin }}=\varepsilon_{\max } / \varepsilon_{\text {lin }} .
$$

This quantity will show the degree of nonlinearity in the building response and the effects of the interference on the amplification of the linear entry strain. This strain is always larger than one.

We will also describe the normalized strain at the end of the analysis, in terms of the ratio

$$
\varepsilon_{\text {norm }}^{\text {end }}=\varepsilon_{\text {end }} \beta_{b} / v_{\text {lin }}=\varepsilon_{\text {end }} / \varepsilon_{\text {lin }} .
$$

This quantity will show the amplitude of the permanent strain (after all of the wave energy exits the building) relative to the linear entry strain. This strain can be larger or smaller than one, and for linear waves, it is zero.

We will also consider the maximum strain normalized by the yielding strain

$$
\varepsilon_{\text {norm }}^{y}=\varepsilon_{\max } / \varepsilon_{y b} .
$$

If this quantity at some point of the building is larger than the maximum allowed ductility $\mu=\varepsilon_{\text {fail }} / \varepsilon_{y b}$, where $\varepsilon_{\text {fail }}$ is the largest strain that can occur in the system, the building may 'collapse'. For linear waves, this normalized strain is smaller than one.

In the further discussions and following our previous work [30], the region $(\eta, x)$ will be divided into three zones-zone $1: Z_{1}=\{(\eta, x) \mid \eta<0.5, \forall x\}$, zone $2: Z_{2}=\{(\eta, x) \mid 0.5 \leqslant \eta, x \sim 0\}$, and zone 3: $Z_{3}=\{(\eta, x) \mid 0.5 \leqslant \eta, x>0\}$.

Figure 3 shows the normalized maximum strains and the zones of the building, where they will occur, versus the dimensionless amplitude of the strong-motion pulse $\alpha$, in the range from 0.0 to 0.8 and for $\gamma=0.44$. We chose this value of $\gamma$ because it corresponds to our best estimate for a building we will discuss later in this paper. This figure has the same form as and has been motivated by the work that led to Figure 8 in [30]. Its purpose is to define the zones where maximum strains will occur as $\alpha$ increases. The data for this figure have been calculated for the layered building model, with properties 


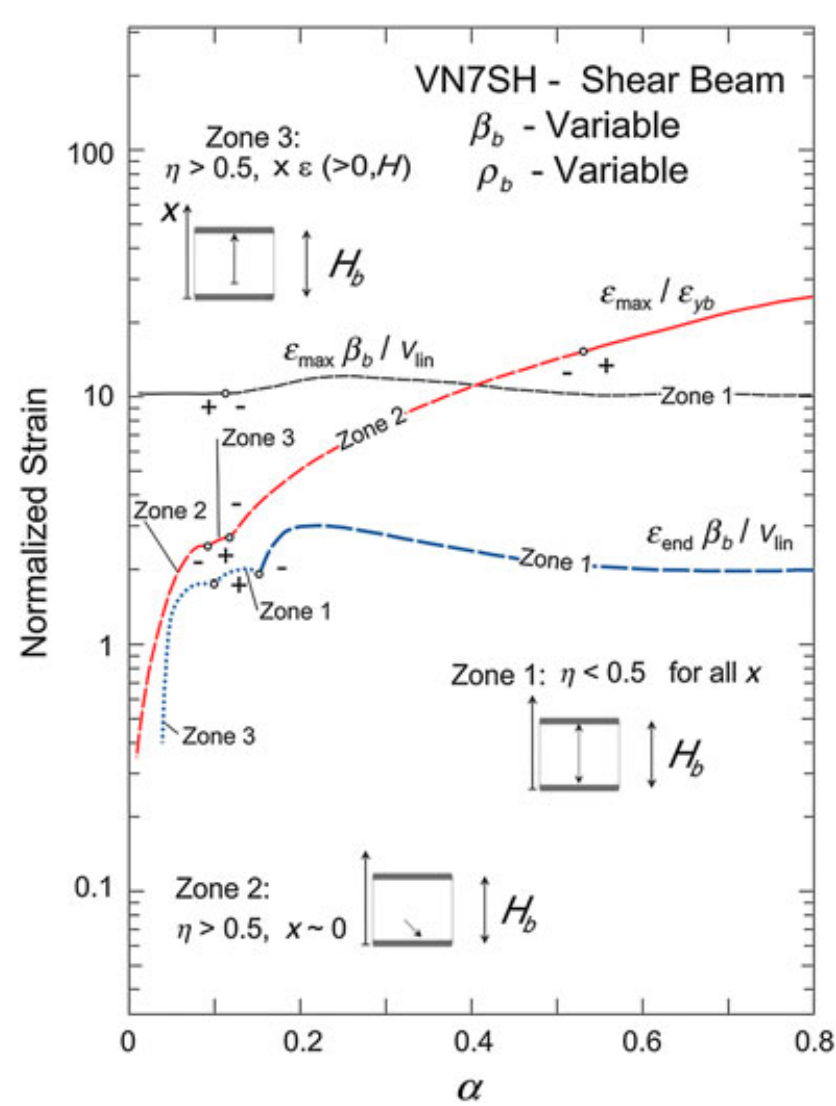

Figure 3. Normalized strains $\varepsilon_{\max } \beta_{b} / v_{\text {lin }}, \varepsilon_{\max } / \varepsilon_{y b}$, and $\varepsilon_{\text {end }} \beta_{b} / v_{\text {lin }}$ versus the dimensionless pulse amplitude, $\alpha$, showing the zones where the largest peak occurs, for $\gamma=0.44$ and for velocity distribution in the building as shown in Table I. Zone 1 corresponds to all $x$ for wavelength of the incident pulse $\lambda_{b}$ longer than $4 H_{b}$. Zones 2 and 3 correspond to the incident pulses with $\lambda_{b}$ shorter than $4 H_{b}$ for maxima occurring at the base of the building $(x \sim 0)$ and between the base and the top of the building $(x>0)$, respectively.

shown in Table I. For $\varepsilon_{\max } \beta_{b} / v_{\text {lin }}$, it is seen that for the range of $\alpha$ we considered here, this strain always occurs in zone 1 (for all $x$ between and including 0 and $H_{b}$ and for wavelengths of the incident pulse $\lambda_{b}$ longer than $4 H_{b}$ ). The normalized strain $\varepsilon_{\max } / \varepsilon_{y b}$ first occurs in zone 2 (for $x \sim 0$ and for wavelengths of the incident pulse $\lambda_{b}$ shorter than $4 H_{b}$ ), for small $\alpha$, then in zone 3 (for $x>0$ and for wavelengths of the incident pulse $\lambda_{b}$ shorter than $4 H_{b}$ ) for a narrow range of $\alpha$ just above 0.1 and then again in zone 2 for larger values of $\alpha$, up to 0.8 . The strain $\varepsilon_{\text {end }} \beta_{b} / v_{\text {lin }}$ first occurs in zone 3 and then in zone 1 for $\alpha$ larger than about 0.1 . Figure 3 describes the normalized strains only for the model in Figure 1 (left), and it will be different for different buildings. It describes the location and the type of strain that will accompany its nonlinear response for excitations by pulses with normalized amplitudes $\alpha$ and durations expressed via $\eta$. Preparing data for such a figure for the model of a building equipped with a real-time structural health-monitoring system and storing this data into the monitoring software, the PEDS results can be used to speed up identification of damage, when the input motion can be decomposed into a sequence of pulses or more generally in terms of wavelets [48].

For excitation consisting of multiple pulses and by assuming that the building did not collapse, the mapping illustrated in Figure 3 will apply to the time intervals between the consecutive pulses, with permanent strains computed by progressive cumulative sums of $\varepsilon_{\text {end }} \beta_{b} / v_{\text {lin }}$ following each pulse respectively. The overall maxima of $\varepsilon_{\max } \beta_{b} / v_{\mathrm{lin}}$ and of $\varepsilon_{\max } / \varepsilon_{y b}$ will be the maxima found among the maxima of each of the intervals following individual pulses. Analyses based on multiple pulses will be of interest in the evaluation of nonlinear response to a specific recorded accelerogram, which has been represented by its equivalent wavelet approximation [48], for example. But, because the first significant excursion to the nonlinear response with permanent deformations will occur during the 
largest pulse, for structural health monitoring based on the PEDS approach described in this paper, analysis in terms of one pulse will suffice.

Figure 4 illustrates the space-frequency $(x-\eta)$ dependence of normalized peak strain $\varepsilon_{\max } \beta_{b} / \nu_{\text {entr }}^{\text {lin }}$ for four normalized excitation amplitudes $(\alpha=0.01,0.05,0.10$, and 0.30 and for $\gamma=0.44)$. The normalized strain along the normalized building height $\left(\chi=2 x / H_{b}\right)$ is plotted at the instant when the absolute maximum occurs for a given frequency $\eta$. This is carried out for all frequencies considered in this work. It is seen that the maxima occur between the fourth and fifth floors and for $\eta$ less than 0.5 -that is, in zone 1 . In Figure 4, the maxima are identified by their amplitudes and coordinates in the plot $\left(\varepsilon_{\text {norm }}, \eta_{\max }, \chi_{\max }\right)$; for example, $(10.5,0.16,0.99)$, where $\eta_{\max }$ and $\chi_{\max }$ are the coordinates in the plots of the points where the maxima of $\varepsilon_{\text {norm }}$ occur.

\section{A COMPARISON WITH DAMAGED FULL-SCALE BUILDING}

We use observations of damage in a seven-story hotel building (VN7SH) in Van Nuys, California, during the 1994 Northridge earthquake to evaluate the inferences of our 1D PEDS model and to test if the previously described approach would have worked in this building if it had been equipped with a real-time health-monitoring system and data on PEDS as described earlier.

\subsection{The building}

The VN7SH (Figure 5(a) and (b)) was damaged by the 1994 Northridge, California earthquake [49-54]. Designed in 1965 and constructed in 1966 [55], it is $18.9 \times 45.7 \mathrm{~m}$ in plan and is $20 \mathrm{~m}$ high. The typical framing consists of four rows of columns spaced on 6.1-m centers in the transverse direction and 5.7-m centers in the longitudinal direction (nine columns) (Figure 5(b)). Spandrel beams surround the perimeter of the structure. Lateral forces in the longitudinal $(\mathrm{E}-\mathrm{W})$ direction are resisted by interior column-slab frames (B and C) and exterior column-spandrel beam frames (A and D). The added stiffness in the exterior frames associated with the spandrel beams creates exterior frames that are roughly twice

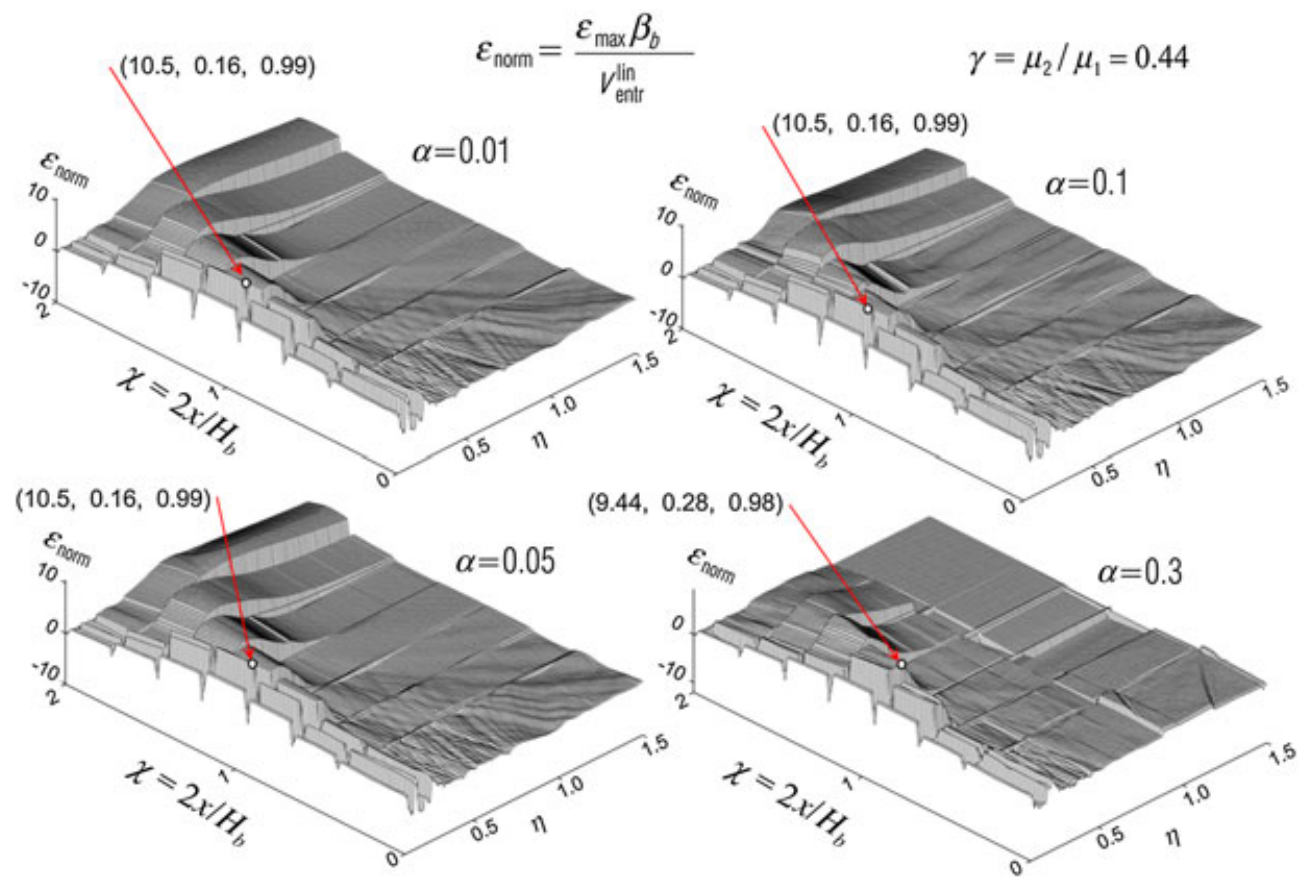

Figure 4. Normalized peaks of strain $\varepsilon_{\text {norm }}=\varepsilon_{\max } \beta_{b} / v_{\text {entr }}^{\text {lin }}$, along the normalized building height $\chi=2 x / H_{b}$, when their maxima occur, versus dimensionless frequency $\eta, \chi=2 x / H_{b}$ for $\gamma=0.44$ and for four dimensionless amplitudes $\alpha=0.010 .05,0.10$, and 0.30 . Maxima are shown accompanied by their dimensionless coordinates (e.g., $(10.5,0.16,0.99)$ for $\left.\left(\left(\varepsilon_{\text {norm }}\right)_{\max }, \eta_{\max }, \chi_{\max }\right)\right)$. 


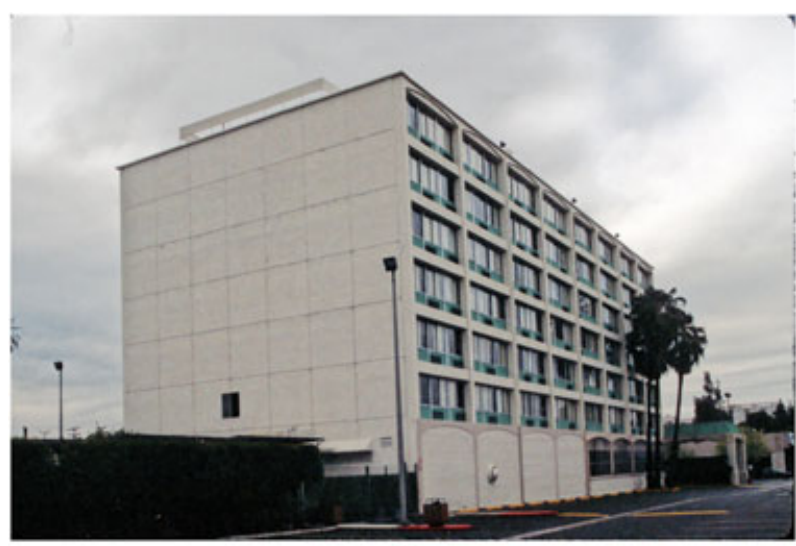

a
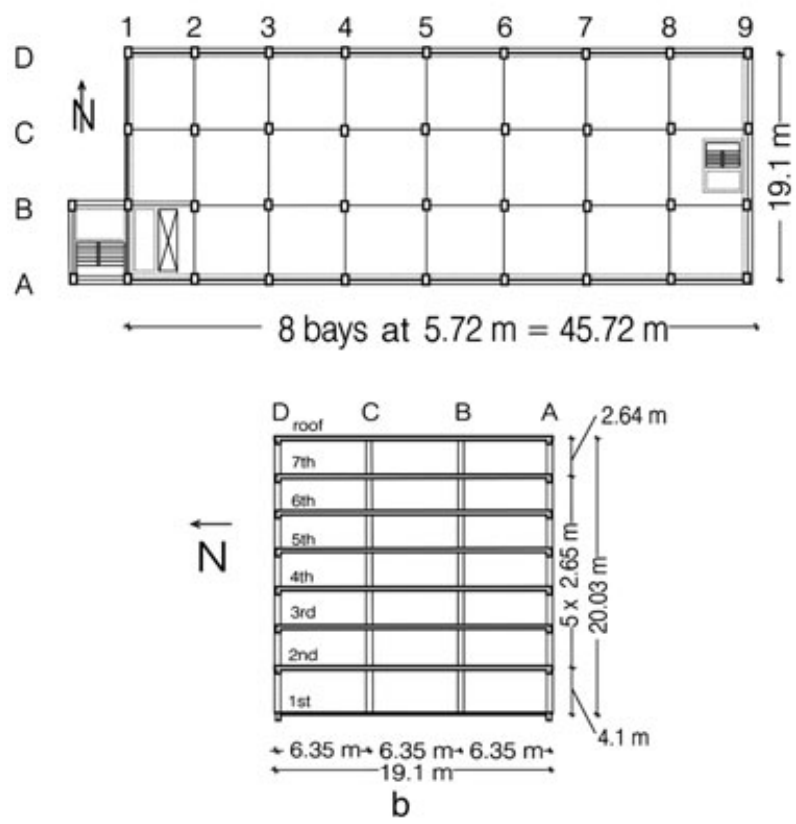

Figure 5. (a) Southwest view of Van Nuys seven-story hotel (VN7SH) building. (b) Typical floor plan (top) and vertical section (bottom) of VN7SH building.

as stiff as the interior frames. The floor system is a reinforced-concrete flat slab, $25.4 \mathrm{~cm}$ thick at the second floor, $21.6 \mathrm{~cm}$ thick at the third to seventh floors, and $20.3 \mathrm{~cm}$ thick at the roof [56-58]. The building is situated on an undifferentiated Holocene alluvium, uncemented and unconsolidated, with a thickness of $<30 \mathrm{~m}$ and an age of $<10,000$ years. The average shear-wave velocity in the top $30 \mathrm{~m}$ of the soil is $300 \mathrm{~m} / \mathrm{s}$, and the soil-boring $\log$ shows that the underlying soil consists primarily of fine sandy silts and silty fine sands. The foundation system consists of $96.5-\mathrm{cm}$-deep pile caps supported by groups of two to four poured-in-place, $61-\mathrm{cm}$-diameter, reinforced-concrete friction piles. These are centered under the main building columns, and all of the pile caps are connected by a grid of beams. Each pile is approximately $12.2 \mathrm{~m}$ long and has a design capacity of over $444.82 \times 10^{3} \mathrm{~N}$ vertical load and up to $88.96 \times 10^{3} \mathrm{~N}$ lateral load. The structure is constructed of normal-weight reinforced concrete [55].

\subsection{Earthquake damage in the VN7SH}

The $M_{\mathrm{L}}=6.4$ Northridge earthquake of January 17, 1994 severely damaged the building, but its possible further damage was probably reduced by nonlinear response of the soils in the area surrounding the building [59-64]. The structural damage was extensive in the exterior north (D) (Figure 5(a), top) and south (A) frames that were designed to take most of the lateral load in the 
longitudinal (E-W) direction. Severe shear cracks occurred at the middle columns of frame A, near the contact with the spandrel beam just below the fifth floor (Figure 6), and those cracks significantly decreased the axial, moment, and shear capacity of the columns. The shear cracks that appeared in the north (D) frame caused minor to moderate changes in the capacities of these structural elements. No major damage to the interior longitudinal (B and $\mathrm{C}$ ) frames was observed, and there was no visible damage to the slabs or around the foundation. The nonstructural damage was significant. Photographs and detailed descriptions of the damage from the earthquake can be found in [49,52-54]. Analysis of the relationship between the observed damage and the changes in equivalent shear-wave velocity along the building height can be found in [4,51]. A discussion of the extent to which this damage has contributed to the changes in the apparent period of the soil-structure system can be found in $[8,9]$.

\subsection{Strong-motion data}

Accelerations during the Northridge 1994 earthquake were recorded by a 13-channel CR-1 central recording system and one tri-component SMA-1 accelerograph (Kinemetrics Inc., Pasadena, CA, USA), with an independent recording system but a common trigger time with the CR-1 recorder $[53,65]$. Figure 7 shows the first $25 \mathrm{~s}$ of the recorded strong-motion displacements in the E-W direction, which corresponds to the longitudinal direction in this building. As already noted, in this paper, we consider only the longitudinal response of this building because it is least affected by SSI, enabling us to analyze its response via a simplified 1D, layered, shear-beam model (Figure 1). The motion in the building was recorded at the ground, at the second, third, and sixth floors, and at the roof.

\subsection{Comparison with predetermined earthquake damage scenario analysis}

Our example of PEDS analysis in the previous text was carried out in terms of only a simple 1D model, excited by a single half-sine pulse (Figure 1). We did not consider a full time history of any recorded strong ground motion because a real PEDS analysis would be carried out before an earthquake occurs, and thus the complete ground motion would not be available. However, as will be seen from the following, this is nevertheless a useful approach because the damaging earthquake motions in the near field contain large strong-motion pulses (e.g., [45,66,67]), which may dominate in the power of incident strong-motion waves [68] and because those tend to be the main contributors to the structural damage. Furthermore, if the proposed PEDS method were not robust and insensitive to the details of strong motion, there would be little point in performing such analyses because it is impossible to predict fine details of any future strong ground motion [69].

As Figure 7 shows, the E-W motion of the ground floor of the VN7SH during the Northridge earthquake had at least two powerful pulses at about 5 and $8 \mathrm{~s}$ after trigger. These pulses propagated up the building and produced damage, which is shown in Figure 6. Their propagation up the building has

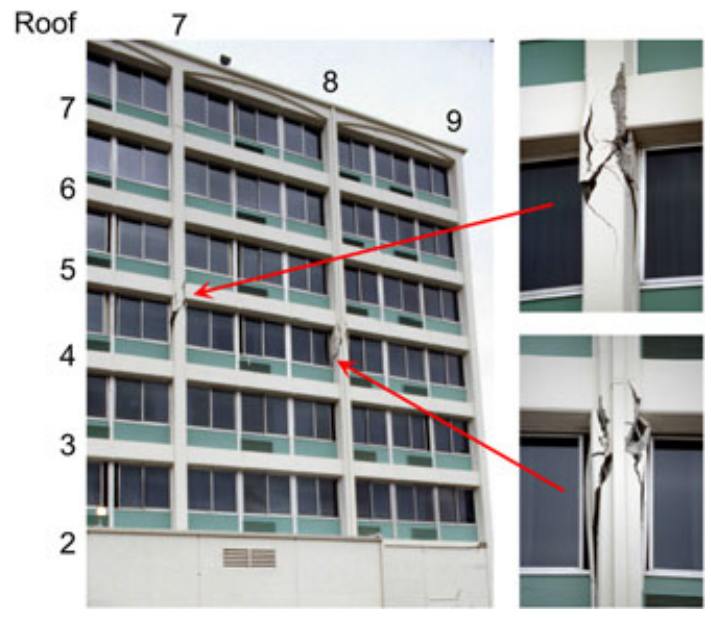

Figure 6. Post-earthquake view of damaged columns A7 and A8 in frame A on the north side of the building. 


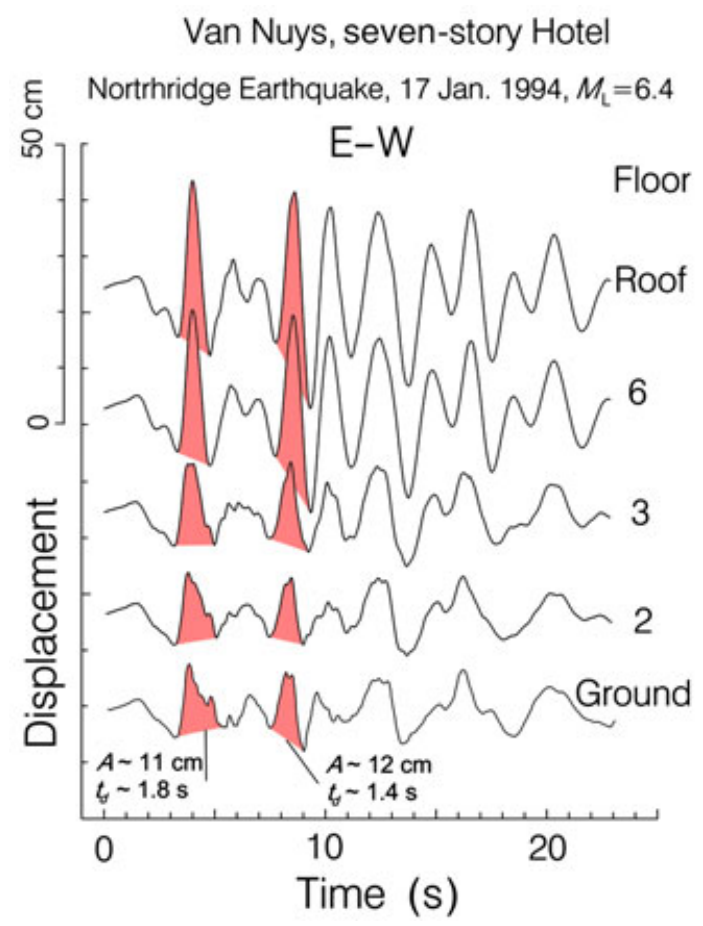

Figure 7. First $25 \mathrm{~s}$ of the E-W recorded earthquake displacements in VN7SH at the ground, the second, third, sixth floors, and at the roof. Pulses in the recorded motion at the ground level, with amplitudes A 11 and $12 \mathrm{~cm}$,

durations 1.8 and $1.4 \mathrm{~s}$, at about 4 and $8 \mathrm{~s}$ after trigger respectively, which propagated up the building are emphasized by shades.

been studied previously [4,29], and the findings are consistent with the interpretation that the significant damage was initiated during excitation by the first pulse and then only augmented by the second. The shaded pulses in Figure 7 can be characterized approximately by amplitudes of half-sine pulses, having about $11-\mathrm{cm}$ and $12-\mathrm{cm}$ amplitudes and durations of 1.8 and $1.4 \mathrm{~s}$, respectively. In terms of the average shear-wave velocity in the building of $99.48 \mathrm{~m} / \mathrm{s}$, these pulses would correspond to $\eta$ of 0.11 and 0.14 and to $\alpha$ equal to 2.2 and 2.4, respectively. In terms of our 1D nonlinear wave analysis, this would predict the first occurrence of nonlinear response in zone $1 \quad(\eta<0.5$ for all $x)$. Examples in Figure 4 show that our PDS analysis would predict the largest transient strains to occur first between the fourth and fifth floors $\left(\varepsilon_{\max } \beta_{b} / v_{\text {entr }}^{\text {lin }} \sim 10\right)$ and for $0.16<\eta<0.28$, which is in excellent agreement with what was observed in the damage patterns after the earthquake (Figure 6). Our analysis predicts initiation of nonlinear response between the fourth and fifth floors for $\alpha$ one order of magnitude smaller than 2.2 to 2.4 corresponding to these two peaks.

\section{DISCUSSION AND CONCLUSIONS}

In this paper, we show how the spatial resolution for identifying the location of structural damage can be improved by comparing the pulses in the ground motion with the pulses for which PEDS have been prepared in advance. Because the pulses in ground motion can be identified in real time after a pulse has evolved and is over completely (say, 1 or $2 \mathrm{~s}$ after the pulse), the real-time health-monitoring software can be programmed to anticipate the consequences in real time as well. We showed how such a prediction agrees with observed damage after the earthquake for a building in Van Nuys, California (VN7SH), for which previous studies have described the time and location of the observed damage. We did not perform further testing of the method because there are not many buildings for which damage and recorded data are as complete as for the VN7SH. Nevertheless, what is clearly seen from the comparison in this paper for this building is that the approach appears to be robust and thus may work for the other buildings as well. 
By formulating the problem via nonlinear wave propagation rather than a vibrational method, we are able to identify the location of damage. Vibrational methods monitor changes in the natural frequencies and thus cannot easily and in real time determine the location of the damage. In principle, damage could be located by monitoring the changes of the mode shapes in the equivalent linear system-whose properties change slowly with time but that requires dense instrumentation-but being not unique and computationally intensive to small stiffness changes, it is not suitable for real-time health-monitoring applications. Another major problem with the vibrational health-monitoring approaches has been the difficulty of separating the changes in system frequencies that result from damaging motions in the structure from those that result from nonlinear response of soil in the SSI process. Obviously, the structural health-monitoring methods, which ignore the contribution of SSI, will not work unless the effects of interaction have been filtered. This is a difficult task, which cannot be solved when working with limited instrumentation and a vibrational method of solution but can be solved in terms of the wave propagation methods, which can be formulated to be less dependent on SSI [3,4].

Another useful application of PEDS is to use them for planning and verification of the structural repair and strengthening strategies. The PEDS can identify the 'weak spots' and the subtle weaknesses in the structural system, like asymmetries, and not the best distributions of overall stiffness, which are rarely considered in forward earthquake-resistant design. We will address these applications of PEDS in future papers.

\section{REFERENCES}

1. Chang PC, Flatau A, Liu SC. Review paper: health monitoring of civil infrastructure. Structural Health Monitoring 2003; 2(3):257-267.

2. Doebling SW, Farrar CR, Prime MB, Shevitz DW. Damage identification and health monitoring of structural and mechanical systems from changes in their vibration characteristics: a literature review, Report LA-13070-MS, Los Alamos National Laboratory, Los Alamos, NM, 1996.

3. Todorovska MI. Seismic Interferometry of Soil-Structure Interaction Model with Coupled Horizontal and Rocking Response. Bulletin of the Seismological Society of America 2009; 99(2A):611-625.

4. Todorovska MI, Trifunac MD. Impulse response analysis of the Van Nuys 7-story Hotel during 11 earthquakes and earthquake damage detection. Structural Control and Health Monitoring 2008a; 15(1):90-116.

5. Todorovska MI, Trifunac MD. Earthquake damage detection in the Imperial County Services Building - I: the data and time-frequency analysis. Soil Dynamics and Earthquake Engineering 2007; 27(6):564-576.

6. Todorovska MI, Trifunac MD. Earthquake damage detection in the Imperial Valley County Services building - III: analysis of wave travel times via impulse response functions. Soil Dynamics and Earthquake Engineering 2008b; 28(5):387-404.

7. Todorovska MI, Trifunac MD. Earthquake damage detection in Imperial County Services Building II: analysis of novelties via wavelets. Structural Control and Health Monitoring 2010; 17: 895-917.

8. Trifunac MD, Ivanović SS, Todorovska MI. Apparent periods of a building I: fourier analysis. Journal of Structural Engineering-ASCE 2001a; 127(5):517-526.

9. Trifunac MD, Ivanović SS, Todorovska MI. Apparent periods of a building II: time-frequency analysis. Journal of Structural Engineering-ASCE 2001b; 127(5):527-537.

10. Sezawa K, Kanai K. Decay in the seismic vibration of a simple or tall structure by dissipation of their energy into the ground. Bulletin of the Earthquake Research Institute 1935; XIII(Part 3):681-697.

11. Sezawa K, Kanai K. Improved theory of energy dissipation in seismic vibrations on a structure. Bulletin of the Earthquake Research Institute 1936; XIV(Part 2):164-168.

12. Trifunac MD. 75th Anniversary of the Response Spectrum Method - a historical review. Soil Dynamics and Earthquake Engineering 2008; 28(9):676-685.

13. Gičev V, Trifunac MD. Amplification of linear strain in a layer excited by a shear wave earthquake pulse. Soil Dynamics and Earthquake Engineering 2010; 30(10):1073-1081.

14. Kanai K. Some problems of seismic vibration of structures. Proceedings of The Third World Conference on Earthquake Engineering, New Zealand 1965; II:260-275.

15. Şafak E Wave propagation formulation of seismic response of multi-story buildings. Journal of Structural EngineeringASCE 1999; 125(4):426-437.

16. Todorovska MI, Trifunac MD. Antiplane earthquake waves in long structures. Journal of Engineering Mechanics-ASCE 1989; 115(12):2687-2708.

17. Todorovska MI, Trifunac MD. Propagation of earthquake waves in buildings with soft 1st floor. Journal of Engineering Mechanics-ASCE 1990a; 116(4):892-900.

18. Todorovska MI, Trifunac MD. Note on excitation of long structures by ground waves. Journal of Engineering MechanicsASCE 1990b; 116(4):952-964.

19. Todorovska MI, Hayir A, Trifunac MD. Antiplane response of a dike on flexible embedded foundation to incident SH-waves. Soil Dynamics and Earthquake Engineering 2001a; 21:593-601.

20. Todorovska MI, Ivanović SS, Trifunac MD. Wave propagation in a seven-story reinforced concrete building, Part I: theoretical models. Soil Dynamics and Earthquake Engineering 2001b; 21(3):211-223.

21. Todorovska MI, Ivanović SS, Trifunac MD. Wave propagation in a seven-story reinforced concrete building, Part II: observed wave numbers. Soil Dynamics and Earthquake Engineering 2001c; 21(3):225-236. 
22. Trifunac MD, Ivanović SS, Todorovska MI. Wave propagation in a seven-story reinforced concrete building, Part III: damage detection via changes in wave-numbers. Soil Dynamics and Earthquake Engineering 2003; 23(1):65-75.

23. Alford RM, Kelly KR, Boore DM. Accuracy of finite-difference modeling of the acoustic wave equation. Geophysics 1974; 39:834-842.

24. Dablain MA. The application of high-order differencing to the scalar wave equation. Geophysics 1986; 51(1):54-66.

25. Tsynkov SV. Numerical solution of problems on unbounded domains: a review. Applied Numerical Mathematics 1998; 27:465-532.

26. Udwadia FE, Trifunac MD. Characterization of response spectra through the statistics of oscillator response. Bulletin of the Seismological Society of America 1974; 64(1):205-219.

27. Gičev V, Trifunac MD. Energy and power of nonlinear waves in a seven-story reinforced concrete building. Indian Society of Earthquake Technology Journal 2007a; 44(1):305-323. (Available from http://home.iitk.ac.in/ vinaykg/iset.html) [accessed on 2007]

28. Gičev V, Trifunac MD. Permanent deformations and strains in a shear building excited by a strong-motion pulse. Soil Dynamics and Earthquake Engineering 2007b; 27(8):774-792.

29. Gičev V, Trifunac MD. Rotations in a shear beam model of a seven-story building caused by nonlinear waves during earthquake excitation. Structural Control and Health Monitoring 2009b; 16(4):460-482.

30. Gičev V, Trifunac MD. Transient and permanent shear strains in a building excited by strong earthquake pulses. Soil Dynamics and Earthquake Engineering 2009c; 29(10):1358-1366.

31. Lax PD, Wendroff B. Difference schemes for hyperbolic equations with high order of accuracy. Communications on Pure and Applied Mathematics 1964; XVII:381-398.

32. Gičev V, Trifunac MD. Transient and permanent rotations in a shear layer excited by strong earthquake pulses. Bulletin of the Seismological Society of America 2009a; 99(2B):1391-1403.

33. Fujino Y, Hakuno M. Characteristics of elasto-plastic ground motion during an earthquake. Bulletin of the Earthquake Research Institute, University of Tokyo 1978; 53:359-378.

34. Hayir A, Todorovska MI, Trifunac MD. Antiplane response of a dike with flexible soil-structure interface to incident $\mathrm{SH}$ waves. Soil Dynamics and Earthquake Engineering 2001; 21:603-613.

35. Lee VW. Investigation of three-dimensional soil-structure interaction. Report No. CE 79-11. Department of Civil Engineering, University of Southern California, Los Angeles, CA, 1979. (Available from: http://www.usc.edu/dept/ civil_eng/Earthquake_eng/) [accessed on 1995]

36. Luco JE, Trifunac MD, Wong HL. On the apparent changes in dynamic behavior of a nine-story reinforced concrete building. Bulletin of the Seismological Society of America 1987; 77(6):1961-1983.

37. Wong HL, Trifunac MD. Interaction of a shear wall with the soil for incident plane SH waves: elliptical rigid foundation. Bulletin of the Seismological Society of America 1974; 64(6):1825-1884.

38. Wong HL, Trifunac MD. Two-dimensional antiplane, building-soil-building interaction for two or more buildings and for incident plane SH waves. Bulletin of the Seismological Society of America 1975; 65(6):1863-1885.

39. Aviles J, Suarez M, Sanchez-Sesma FJ. Effects of wave passage on the relevant dynamic properties of structures with flexible foundation. Earthquake Engineering and Structural Dynamics 2002; 31:139-159.

40. Jalali RS, Trifunac MD. Response spectra for near-source, differential and rotational strong motion. Bulletin of the Seismological Society of America 2009; 99(2B):1404-1415.

41. Todorovska MI, Trifunac MD, Lee, VW. Shaking hazard compatible methodology for probabilistic assessment of permanent ground displacement across earthquake faults. Soil Dynamics and Earthquake Engineering 2007; 27(6):586-597.

42. Trifunac MD. Curvograms of strong earthquake ground motion. Journal of Engineering Mechanics—ASCE 1990; 116(6): $1426-1432$.

43. Trifunac MD. Empirical criteria for liquefaction in sands via standard penetration tests and seismic wave energy. Soil Dynamics and Earthquake Engineering 1995; 14(6):419-426.

44. Trifunac MD. Differential earthquake motion of building foundations. Journal of Structural Engineering—ASCE 1997; 123(4): 414-422.

45. Trifunac MD. The role of strong motion rotations in the response of structures near earthquake faults. Soil Dynamics and Earthquake Engineering 2009a; 29(2):382-393.

46. Trifunac MD, Gičev V. Response spectra for differential motion of columns, paper II: out-of-plane response. Soil Dynamics and Earthquake Engineering 2006; 26(12):1149-1160.

47. Trifunac MD, Todorovska MI. Response spectra and differential motion of columns, with M.I. Todorovska. Earthquake Engineering and Structural Dynamics 1997a; 26(2):251-268.

48. Todorovska MI, Meidani H, Trifunac MD. Wavelet approximation of earthquake strong ground motion - goodness of fit for a database in predicting nonlinear structural response. Soil Dynamics and Earthquake Engineering 2009; 29(4): $742-751$.

49. Ivanović SS, Trifunac MD, Novikova EI, Gladkov AA, Todorovska MI. Instrumented 7 -storey reinforced concrete building in Van Nuys, California: description of damage from the 1994 Northridge earthquake and strong motion data. Report CE 99-02. Department of Civil Engineering, University of Southern California, Los Angeles, CA, 1999. (Available from: http:// www.usc.edu/dept/civil_eng/Earthquake_eng/) [accessed on 1999]

50. Ivanović SS, Trifunac MD, Novikova EI, Gladkov AA, Todorovska MI. Ambient vibration tests of a seven-story reinforced concrete building in Van Nuys, California, damaged by the 1994 Northridge earthquake. Soil Dynamics and Earthquake Engineering 2000; 19(6):391-411.

51. Ivanović SS, Trifunac MD, Todorovska MI. On identification of damage in structures via wave travel times, with S.S. Ivanovic and M.I. Todorovska, Proceedings of the NATO Advanced Research Workshop on Strong-Motion Instrumentation for Civil Engineering Structures, June 2-5, 1999, Istanbul, Turkey. Kluwer Academic Publishers: Dordrecht, 2001; 447-468.

52. Trifunac MD, Hao TY. 7-Storey Reinforced Concrete Building in Van Nuys, California: Photographs of the Damage from the 1994 Northridge Earthquake. Report CE 01-05. Department of Civil Engineering, University of Southern California, Los Angeles, CA, 2001. (Available from: http://www.usc.edu/dept/civil_eng/Earthquake_eng/) [accessed on 2001]

53. Trifunac MD, Ivanović SS, Todorovska MI. Instrumented 7-storey reinforced concrete building in Van Nuys, California: description of damage from the 1994 Northridge earthquake and strong motion data. Report CE 99-02. Department of Civil 
Engineering, University of Southern California, Los Angeles, CA, 1999a. (Available from: http://www.usc.edu/dept/ civil_eng/Earthquake_eng/) [accessed on 1999]

54. Trifunac MD, Ivanović SS, Todorovska MI, Novikova EI, Gladkov AA. Experimental evidence for flexibility of a building foundation supported by concrete friction piles. Soil Dynamics and Earthquake Engineering 1999b; 18(3):169-187.

55. Blume and Assoc. In Holiday Inn, in San Fernando, California, earthquake of February 9, 1971, Murphy LM (ed.). U.S. Department of Commerce, National Oceanic and Atmospheric Administration: Washington, DC, 1973.

56. Islam MS. Analysis of the response of an instrumented 7-story non ductile concrete frame building damaged during the Northridge earthquake. Professional Paper 96-9, Los Angeles Tall Buildings Structural Design Council Annual Meeting, Los Angeles, CA, 1996.

57. Li YR, Jirsa JO. Nonlinear analyses of an instrumented structure damaged in the 1994 Northridge earthquake. Earthquake Spectra $1998 ; \mathbf{1 4}(2): 265-283$.

58. Trifunac MD, Ivanović SS. Analysis of drifts in a seven-story reinforced concrete structure. Report No. CE 03-01. Department of Civil Engineering, University of Southern California, Los Angeles, CA, 2003. (Available from: http://www. usc.edu/dept/civil_eng/Earthquake_eng/) [accessed on 2003]

59. Trifunac MD, Todorovska MI. Nonlinear soil response - 1994 Northridge California, earthquake. Journal of Geotechnical Engineering, ASCE 1996; 122(9):725-735.

60. Trifunac MD, Todorovska MI. Northridge, California, earthquake of 17 January 1994: density of pipe breaks and surface strains. Soil Dynamics and Earthquake Engineering 1997b; 16(3):193-207.

61. Trifunac MD, Todorovska MI. Northridge, California, earthquake of 1994: density of red-tagged buildings versus peak velocity and intensity of shaking. Soil Dynamics and Earthquake Engineering 1997c; 16(3):209-222.

62. Trifunac MD, Todorovska MI. Reduction of structural damage by nonlinear soil response. Journal of Structural Engineering-ASCE 1999; 125(1):89-97.

63. Trifunac MD, Todorovska MI, Ivanović SS. A note on distribution of uncorrected peak ground accelerations during the Northridge, California, earthquake of 17 January 1994. Soil Dynamics and Earthquake Engineering 1994; 13(3):187-196.

64. Trifunac MD, Todorovska MI, Ivanović SS. Peak velocities, and peak surface strains during Northridge, California, earthquake of 17 January 1994. Soil Dynamics and Earthquake Engineering 1996; 15(5):301-310.

65. Shakal A, Huang M, Darragh R, Cao T, Sherburne R, Malhotra P, Cramer C, Syndov R, Graizer V, Maldonado G, Peterson C, Wimpole J. CSMIP strong-motion records from the Northridge, California, earthquake of 17 January 1994. Report No. OSMS 94-07. California Department of Conservation, Division of Mines and Geology, Sacramento, CA, 1994.

66. Housner GW, Trifunac MD. Analysis of accelerograms - Parkfield earthquake. Bulletin of the Seismological Society of America 1967; 57(6):1193-1220.

67. Trifunac MD. Rotations in structural response. Bulletin of the Seismological Society of America 2009b; 99(2B):968-979.

68. Trifunac MD. Nonlinear problems in earthquake engineering. In Encyclopedia of Complexity and System Science Vol. 3, Meyers RA (ed.). Springer: New York, 2009c; 2421-2437.

69. Trifunac MD. A method for synthesizing realistic strong ground motion. Bulletin of the Seismological Society of America 1971; 61(6):1739-1753. 